Tropical Journal of Pharmaceutical Research February 2017; 16 (2): 357-361

ISSN: $1596-5996$ (print); 1596-9827 (electronic)

(c) Pharmacotherapy Group, Faculty of Pharmacy, University of Benin, Benin City, 300001 Nigeria.

All rights reserved.

Available online at http://www.tjpr.org

Original Research Article

http://dx.doi.org/10.4314/tjpr.v16i2.14

\title{
Analysis of the effect of Qizhuyigan on liver function in a mouse model of immunological liver injury
}

\author{
Xiao-Qi Zhang*, Kui-Chen Li and Shu-Min He \\ Pharmacy Department, Binzhou People's Hospital, Binzhou, Shandong, 256600, PR China
}

${ }^{*}$ For correspondence: Email: zxqzhangxqi@163.com

Received: 14 September 2016

Revised accepted: 19 January 2017

\begin{abstract}
Purpose: To assess the protective effect of Qizhuyigan capsules containing an herbal mixture on liver function in a mouse model of immunological liver injury and to explore the mechanism of action.

Methods: One hundred and twenty mice were randomly divided into four groups: control, test, bifendate, and Qizhuyigan. Immunological liver injury was induced in all groups except the control group. Mice in the control group and the test group were gavaged with $2.5 \mathrm{~g} / \mathrm{kg}$ tap water, mice in the bifendate group were gavaged with $12 \mathrm{mg} / \mathrm{kg}$ bifendate in water, and mice in the Qizhuyigan group were gavaged with $1,000 \mathrm{mg} / \mathrm{kg}$ of an aqueous solution containing the contents of a Qizhuyigan capsule. The gavage continued for 10 days. Changes in liver function-related indices, such as the levels of alanine aminotransferase (ALT), aspartate aminotransferase (AST), malonaldehyde (MDA), superoxide dismutase (SOD), tumor necrosis factor $\alpha$ (TNF- $\alpha$ ), and interleukin 6 (IL-6), were assessed.

Results: Compared with the test and bifendate groups, the Qizhuyigan group exhibited lower serum $A L T$ (98.3 U/L \pm 8.7 U/L vs. 224.7 U/L $\pm 18.4 \mathrm{U} / \mathrm{L}$ vs. $132.8 \mathrm{U} / \mathrm{L} \pm 9.4 \mathrm{U} / \mathrm{L}) ; A S T(165.5 \mathrm{U} / \mathrm{L} \pm 12.1 \mathrm{U} / \mathrm{L}$ vs. $362.6 \mathrm{U} / \mathrm{L} \pm 16.6 \mathrm{U} / \mathrm{L}$ vs. $224.6 \mathrm{U} / \mathrm{L} \pm 12.2 \mathrm{U} / \mathrm{L})$; and MDA levels $(12.7 \pm 2 \mu \mathrm{mol} / \mathrm{L}$ vs. $31.3 \pm 6.60$ $\mu \mathrm{mol} / \mathrm{L}$ vs. $14.4 \pm 2.3 \mu \mathrm{mol} / \mathrm{L}) ;$ a higher SOD level; and reduced TNF- $\alpha$ and IL-6 levels. The differences of the above indices had statistical significance $(p<0.05)$.

Conclusion: Qizhuyigan exerted a protective effect in a mouse model of immunological liver injury.
\end{abstract}

Keywords: Qizhuyigan capsule, Immunological liver injury, Biochemical parameters

Tropical Journal of Pharmaceutical Research is indexed by Science Citation Index (SciSearch), Scopus, International Pharmaceutical Abstract, Chemical Abstracts, Embase, Index Copernicus, EBSCO, African Index Medicus, JournalSeek, Journal Citation Reports/Science Edition, Directory of Open Access Journals (DOAJ), African Journal Online, Bioline International, Open-J-Gate and Pharmacy Abstracts

\section{INTRODUCTION}

Viral hepatitis has various routes of infection, and the population suffering from viral hepatitis is widespread. China has the largest population of hepatitis B patients worldwide and the morbidity associated with hepatitis $C$ is increasing annually [1]. Persistent infection and repeated viral attacks are important factors in liver cirrhosis and primary hepatic carcinoma $(\mathrm{PHC})[2]$.

Currently, Western medicine usually treats viral hepatitis by inhibiting virus replication, protecting hepatocytes, reducing transaminases, and improving immune function. Drugs such as nucleosides and interferon have good short-term curative effects, but their long-term effects are unsatisfactory. Moreover, the high medical expenses, the severe toxic side effects of drugs, and viral drug resistance, are problematic [3,4]. It would be very useful to identify a drug that inhibits acute liver immunoreaction and lipid peroxidation, removes free radicals, reduces the levels of cytotoxic factors, and modulates liver metabolism $[5,6]$.

Schemes based on traditional Chinese medicine have long been used to treat liver disease, and 
valuable experience has been accumulated. Recently, the pharmacological mechanisms and the clinical medicinal value of some Chinese herbal medicines have been clarified, and their lower costs, fewer toxic effects, and reliable longterm curative effects make them worthy of study [7].

Qizhuyigan capsule contains seven traditional Chinese medicinal materials, including the root of red-rooted salvia, felwort, white atractylodes rhizome, Astragalus membranaceus, and radix isatidis. The preparation can eliminate dampheat, and regulates the liver and spleen. The capsule is used clinically to treat various types of chronic hepatitis, and has good curative effects, but its mechanism of action has not been determined [8].

The study mainly explored the mechanism of action of Qizhuyigan on liver function in a mouse model of immunological liver injury to provide a theoretical foundation for the treatment of immunological liver injury and offer an experimental basis for further development of the Qizhuyigan capsules.

\section{EXPERIMENTAL}

\section{Drugs and reagents}

Qizhuyigan capsules formulated from $15 \mathrm{~g}$ of the root of red-rooted salvia, $15 \mathrm{~g}$ rough gentian, 15 g Rhizoma Atractylodis Macrocephalae, $15 \mathrm{~g}$ Astragalus membranaceus, $12 \mathrm{~g}$ Radix isatidis, $10 \mathrm{~g}$ Semen brassicae, and $6 \mathrm{~g}$ Curcuma zedoary were obtained from the Binzhou People's Hospital. Bifendate pills (batch number: 2014122081) were purchased from Guangzhou Baiyun Moutain Xingqun Pharmacy Co., Ltd. (China), malondialdehyde (MDA), superoxide dismutase (SOD), allophanamide (Shanghai Hongshun Biotech. Co., Ltd., China), tumour necrosis factor- $\alpha$ (TNF- $\alpha$ ) enzyme-linked immunosorbent assay (ELISA), and interleukin 6 (IL-6) kits (Beijing Biolab Science and Technology Ltd., China) were also purchased.

\section{Animals and instruments}

One hundred and twenty male mice (body weight range $18-22 \mathrm{~g}$ ) were obtained from the Experimental Animal Centre of Binzhou Medical College, Shandong, China, and were acclimated for $7 \mathrm{~d}$ in the Binzhou People's Hospital, Shandong, China. Instruments used included an AU5800 automatic biochemical analyser (Beckman Coulter, Inc., USA), a TG18G-II highspeed centrifuge (Shanghai Yanqi Biotechnology Co., Ltd., China), an RX-MBY enzyme-labelling instrument

(Beijing

Ruixi

Science and Technology Ltd., China), a UV-765 ultraviolet and visible spectrophotometer (Shanghai Junke Biotech. Co., Ltd., China), and an AUW120D analytical balance (Shimadzu Inc., Japan).

\section{Grouping and modelling}

The 120 mice were divided randomly into control, test, bifendate, and Qizhuyigan groups. The model used was reported previously [9]. Specifically, except for the control group, the other groups were gavaged with tap water at 2.5 $\mathrm{g} / \mathrm{kg}$. Mice in the bifendate group were gavaged with $12 \mathrm{mg} / \mathrm{kg}$ of the drug, and mice in the Qizhuyigan group were gavaged with water containing the contents of a Qizhuyigan capsule $(1,000 \mathrm{mg} / \mathrm{kg})$, for 10 days. On the last day of the experiment, all mice except those in the blank control group were injected intravenously with lipopolysaccharides $(0.4 \mathrm{mg} / \mathrm{kg})$ through the tail vein after the last dosing. Furthermore, each mouse was fixed with a fixator, with its tail outside the fixators. The tail was repeatedly wiped with of $75 \%(\mathrm{v} / \mathrm{v})$ ethyl alcohol. The tail vein was punctured with a syringe at an angle of $30^{\circ}$ and a white line was seen along the vein. The absence of resistance during drug injection indicated that the tip of the needle had penetrated the vein, and residual drug was then injected continuously. Then, the needle was removed and the injection site was pressed with a cotton swab to stop the bleeding. Mice were provided with water, but no food, after the injection. They were assessed $12 \mathrm{~h}$ after the injection.

This study was approved by the Medical Ethics Committee of Binzhou People's Hospital (approval no. ZXQ20160115BZ) and followed the protocols set out in the Declaration of Helsinki [10].

\section{Determination of biochemical parameters}

After the mice were anaesthetised with diethyl ether, the eyeballs were removed with tweezers. Next, $1.5 \mathrm{~mL}$ of blood was collected using a sterile blood collection tube and centrifuged at (5,000 revolutions/min at a centrifugal radius of 6 $\mathrm{cm}$ for $10 \mathrm{~min}$, and serum was recovered. An automatic biochemical analyser was used to measure levels of alanine aminotransferase (ALT) and aspartate aminotransferase (AST). Liver tissues were collected, washed with normal saline at $4^{\circ} \mathrm{C}$, and dried with filter paper. Samples $(0.2 \mathrm{~g})$ of liver tissues were taken and $10 \%(\mathrm{w} / \mathrm{v})$ homogenates were prepared, and centrifuged at 4,500 revolutions/min at a 
centrifugal radius of $6 \mathrm{~cm}$ for $10 \mathrm{~min}$. The supernatants were removed and the levels of MDA, SOD, TNF- $\alpha$, and IL-6 measured following standard operating instructions provided with the kits.

\section{Statistical analysis}

Analyses were conducted using SPSS version 20.0. Data are expressed as means \pm standard deviation (SD). Enumerated data were assessed using $X^{2}$ tests, whereas categorical data were processed using $t$-tests. $P<0.05$ was taken to indicate statistical significance.

\section{RESULTS}

\section{Serum ALT and AST levels}

The serum ALT and AST levels of the test group were significantly higher than those of the control group (both $p<0.05$ ), indicating that the animal model had been established successfully. The serum ALT and AST levels of the bifendate and Qizhuyigan groups were much lower than those of the test group (both $p<0.05$ ). The ALT and AST levels were lowest in the Qizhuyigan group (Table 1).

Table 1: Serum ALT and AST levels in the various groups (mean $\pm \mathrm{SD}, \mathrm{U} / \mathrm{L}, \mathrm{N}=30$ )

\begin{tabular}{lcc}
\hline Group & ALT & AST \\
\hline Control & $43.10 \pm 6.30$ & $98.40 \pm 10.40$ \\
Test & $224.70 \pm 18.40^{\circ}$ & $362.60 \pm 16.60$ \\
Bifendate & $132.80 \pm 9.40^{*}$ & $224.60 \pm 12.20^{* \#}$ \\
$\begin{array}{l}\text { Qizhuyigan } \\
\text { capsule }\end{array}$ & $98.30 \pm 8.70^{* \#}$ & $165.50 \pm 12.10^{* \#}$ \\
\hline${ }^{*} p<0.05$ compared with that of the blank control \\
group; ${ }^{*} p<0.05$ compared with that of the test group
\end{tabular}

\section{MDA and SOD contents of liver homogenates}

Compared with the control, SOD levels in the hepatic tissue homogenate of the test group decreased, but MDA levels increased $(p<0.05)$, indicating peroxidation damage. Compared with the bifendate group, the Qizhuyigan group exhibited clearly reduced MDA levels in hepatic tissue homogenate $(p<0.05)$ and increased SOD levels $(p<0.05)$. MDA and SOD contents changed the most in the Qizhuyigan group, indicating that Qizhuyigan enhanced antilipid peroxidation ability (Table 2).

\section{TNF- $\alpha$ and IL- 6 contents of liver homogenates}

Compared with the control group, the TNF- $\alpha$ and IL-6 levels in the liver homogenate of the test group were significantly increased (both $p<$ 0.05), indicating more serious damage to liver tissues in the former group. Compared with the test group, the bifendate group and the Qizhuyigan group exhibited significantly reduced TNF- $\alpha$ and IL-6 levels (both $p$ values < 0.05); this was especially true of the Qizhuyigan group, suggesting that the anti-hepatic injuryability of Qizhuyigan may be related to inhibition of the release of the cytotoxic factors TNF- $\alpha$ and IL-6 (Table 3).

Table 2: MDA and SOD contents of liver homogenates of the groups (mean $\pm S D, N=30$ )

\begin{tabular}{lcc}
\hline Group & MDA $(\boldsymbol{\mu m o l} / \mathrm{L})$ & SOD $(\mathbf{U} / \mathbf{g})$ \\
\hline Control & $4.70 \pm 1.40$ & $33.70 \pm 4.70$ \\
Test & $31.30 \pm 6.60^{*}$ & $10.20 \pm 2.40^{*}$ \\
Bifendate & $14.40 \pm 2.30^{*}$ & $27.50 \pm 3.70^{* \#}$ \\
Qizhuyigan & $12.70 \pm 2^{* \#}$ & $29.70 \pm 4^{* \#}$ \\
capsule & \\
\hline${ }^{*} p<0.05$ compared with the blank control group; ${ }^{\#} p<$ \\
0.05 compared with the test group
\end{tabular}

Table 3: Comparison of TNF- $\alpha$ and IL-6 contents in liver homogenates of the various groups (mean $\pm S D$, $\mathrm{ng} / \mathrm{L}, \mathrm{N}=30$ )

\begin{tabular}{lcc}
\hline Group & TNF- $\alpha$ & IL-6 \\
\hline Control & $112.90 \pm 21.70$ & $53.20 \pm 12.70$ \\
Test & $364.90 \pm 40.90$ & $229.20 \pm 33.90$ \\
Bifendate & $156.70 \pm 25.90^{\circ}$ & $154.70 \pm 18.40^{* \#}$ \\
Qizhuyiga & $138.30 \pm 23.70^{* \#}$ & $139.40 \pm 16^{* \#}$ \\
n capsule & & \\
\hline${ }^{*} p<0.05$ compared with the blank control group; ${ }^{\#} p<$ \\
0.05 compared with the test group
\end{tabular}

\section{DISCUSSION}

Viral hepatitis is a relatively common infectious disease. The occurrence of immunoreactions in the liver is an important factor causing liver injuries in patients with viral hepatitis. Currently, effective drugs for treating chronic viral hepatitis are lacking, but good curative effect may be achieved if the treatment is focused on regulating immunity. The occurrence of liver injury in patients with chronic viral hepatitis appears to be significantly correlated with immune dysfunction and immunodeficiency [11]. The animal model of immunological liver injury used in this study was associated with extensive cytokine release (e.g., TNF- $\alpha$ and IL-6) and oxygen radicals, similar to the pathogenesis of liver injury induced by chronic viral hepatitis. Thus, the mouse model was suitable for the purpose [12].

Traditional Chinese medicine suggests that liver injury is caused by insufficient anti-pathogenic energy, damp-heat, and pestilent toxin. The basic therapies used to treat Chronic Hepatitis B (CHB) are based on toxin elimination, phlegm reduction, relief of fatigue, correction of deficiencies, and tonification. Traditional Chinese 
medicine can help treat various difficult diseases, and scholars are focusing on applying traditional Chinese medicine to develop drugs to treat liver diseases.

The Qizhuyigan capsule used in this study was developed based on clinical experience using traditional Chinese medicine to treat viral hepatitis, along with features of traditional Chinese medicine, such as diagnosis and treatment based on an overall analysis of the illness and the patient's condition, as well as modern pharmacology. The capsule consists of seven traditional Chinese medicine materials, including the root of red-rooted salvia, felwort, white atractylodes rhizome, Astragalus membranaceus, and radix isatidis. Astragalus membranaceus is frequently used in traditional Chinese medicine, with effects such as tonifying qi, lifting yang, strengthening the exterior, reducing sweat, inducing diuresis to alleviate oedema, and promoting fluid and blood production. Work using modern pharmacological techniques [13,14] has revealed that Astragalus membranaceus contains active ingredients, such as astragaloside, which can improve cardiopulmonary function, enhance immunity and promote the body's resistance to disease, specifically its ability to resist viruses.

ALT and AST levels can directly reflect the degree of liver injury. Previous research has found that damage to $1 \%$ of hepatocytes can double the levels of ALT and AST in the liver [15]. Levels of ALT and AST in the test group were clearly increased compared with the blank control group, and those in the bifendate and Qizhuyigan groups were significantly decreased, indicating that Qizhuyigan had a protective effect in this mouse model of immunological liver injury.

Lipid peroxidation plays an important role in the occurrence and development of immunological liver injury. MDA is the end product of lipid peroxidation, the content of which is positively proportional to the degree of lipid peroxidation [16].

SOD is important in balancing oxidant and antioxidant content in the body, and can remove superoxide anion free radicals and protect cells from damage [17]. Thus, levels of SOD and MDA can reflect the degree of damage caused by peroxidation. Our results indicate that Qizhuyigan can significantly lower MDA and increase SOD in mice, indicating positive anti-lipid peroxidation effects.

TNF- $\alpha$ not only directly kills hepatocytes, but also promotes liver injury [18]. IL-6 has functions in regulating immunoresponses and promoting the growth of hepatocytes [19]. The results of this study suggest that Qizhuyigan may effectively protect the liver by significantly lowering TNF- $\alpha$ and IL-6 content and reducing the release of inflammatory factors.

\section{CONCLUSION}

Qizhuyigan protected mouse liver function in animals with induced immunological liver injury. The mechanism of action appeared to be related primarily to the inhibition of immune function and lipid peroxidation in the liver, thereby providing some theoretical pharmacological foundation for the clinical treatment of chronic viral hepatitis using Qizhuyigan capsules.

\section{DECLARATIONS}

\section{Acknowledgement}

The authors sincerely thank all those who supported this work.

\section{Conflict of Interest}

No conflict of interest associated with this work.

\section{Contribution of Authors}

The authors declare that this work was done by the authors named in this article and all liabilities pertaining to claims relating to the content of this article will be borne by them.

\section{Open Access}

This is an Open Access article that uses a funding model which does not charge readers or their institutions for access and distributed under the terms of the Creative Commons Attribution License (http://creativecommons.org/licenses/by 14.0) and the Budapest Open Access Initiative (http://www.budapestopenaccessinitiative.org/rea d), which permit unrestricted use, distribution, and reproduction in any medium, provided the original work is properly credited.

\section{REFERENCES}

1. Lin X, Huang QF, Zhang SJ, Huang RB. Protective effect of terpenoids of liuyueqing on immunological liver injury in mice. Chin J Exp Trad Med Form 2010; 16(15): 117119.

2. Imose $M$, Nagaki $M$, Kimura K, Takai S, Imao M, Naiki T, Osawa Y, Asano T, Hayashi H, Moriwaki H. Leflunomide protects from $T$-cell-mediated liver injury in mice through 
inhibition of nuclear factor kappaB. Hepatology 2004; 40(5): 1160-1169.

3. Kajiya $M$, Sato $K$, Silva MJB, Ouhara $K$, Do PM, Shanmugam KT, Kawai T. Hydrogen from intestinal bacteria is protective for Concanavalin A-induced hepatitis. Biochem Biophys Res Commun 2009; 386(2): 316-321.

4. Shin JW, Wang JH, Kim HG, Park GJ, Bok HS, Son CG. CGX, a traditional Korean medicine ameliorates concanavalin A-induced acute liver injury. Food Chem Toxicol 2010; 48(12): 3308-3315.

5. Tsochatzis EA, Bosch J, Burroughs AK. Liver cirrhosis. Lancet 2014; 383(9930): 1749-1761.

6. Liu P, Hu YY, Liu C, Xu LM, Liu CH, Sun KW, Hu DC, Yin $Y K$, Zhou $X Q$, Wan $M B$, et al. Multicenter clinical study about the action of Fuzheng Huayu Capsule against liver fibrosis with chronic hepatitis B. J Chin Integr Med 2003; 1(2): 89-98, 102.

7. Xie RH, Liu YH, Zhao YR. Analysis of curative effect of Ganlong capsule in treating chronic hepatitis B. Chin J Integr Trad West Med Liver Dis 2003; 13(6): 366.

8. Bai SL, Hu AP, Liu JZ, Zhao YQ. Protective effect of niuhuangshen capsules on immunological liver injury in mice. World J Integr Trad West Med 2014; 9(2): 147150.

9. Feng $T B$, Tian GJ, Li H, Tang $M Z$, Chen $P Q$, Wang $X H$, Zhang FX. An experimental study of phyllanthus urinaria for counteracting immune liver injury in mice. Trad Chin Drug Res Clin Pharmacol 2015; 16(5): 343-345.

10. Declaration of Helsinki. The 59th World Medical Conference, 2008.

11. Liu GT. Present status of hepatitis drugs and ETs perspective in Society office of China Association for sciences and technology Research on prevention and therapy of viral hepatitis Beijing. China Sci Tech Press 1991; 16(3): 337-341.

12. Tracey KJ, Cerami A. Tumor necrosis factor: a pleiotropic cytokine and therapeutic target. Annu Rev Med 1994; 45: 491-503.

13. Zhang LL, Zhou Q, Wu LL, Sun LL. Determination of Astragaloside IV in gengnian tiaohe granula by HPLCELSD. Trad Chin Drug Res Clin Pharmacol 2013; 24(6): 619-621.

14. He DY, Zhong YG, Liao HY, Li J, Zhang T, Liu H. Determination of Astragaloside in fuzheng yiwei oral liquid by HPLC-ELSD. Pharm J Chin People Liberat Army 2013; 29(4): 367-368,371.

15. Lin X, Huang QF, Zhang SJ, Huang RB. Protective effect of the water extract from helicteres angustifolia on immunological liver injury in mice. Chin J Mod Appl Pharm 2012; 29(1): 1-5.

16. Stebbing ARD. Tolerance and hormesis-increased resistance to copper in hydroids linked to hormesis. Mar Environ Res 2002; 54(3-5): 805-809.

17. Chen H, Wang HJ, Li XF. Change of NO, SOD and MDA in methamphetamine-treated rat brain and their correlation. Chin J of Drug Dependence 2007; 16(2): 102-104.

18. Yin HZ, Zhao CY, Liu YH, Song YG. Role of two kinds of adipokines on hepatocellular apoptosis in mice with acute liver injury. Basic Clin Med 2009; 29(10): 10701074.

19. Sun J, Walsh M, Villarino AV, Cervi L, Hunter CA, Choi Y, Pearce EJ. TLR ligands can activate dendritic cells to provide a MyD88-dependent negative signal for Th2 cell development. J Immunol 2005; 174(2): 742-751. 